\title{
The Persistence of Gender Struggles in Nordic Research and Innovation
}

\author{
Gabriele Griffin ${ }^{1 *}$, Marja Vehviläinen ${ }^{2}$
}

Published: September 1, 2021

\begin{abstract}
Despite being renowned for their gender equality, the Nordic countries continue to suffer from persistent inequalities including in research and innovation (R\&I) as an employment field. Drawing on interviews conducted between 2017 and 2020 with women and men working in R\&I inside and outside of the academy, and on Charles Tilly's (1998) conceptualisations of durable inequalities, the authors find that specific and cumulative gendered disadvantages accompany women's R\&I careers at each of the four researcher career stages (doctoral student, postdoc, researcher/lecturer, full professor), in particular through unquestioned informal everyday practices.
\end{abstract}

Keywords: durable inequality, gender inequality, researcher career stages, research and innovation, informal practices, Nordic countries

\section{INTRODUCTION}

The persistence of gender inequalities throughout the western world into the $21^{\text {st }}$ century is well documented in numerous studies and statistics (OECD; SHE Figures) despite the fact that all western countries have national, regional, and local equality legislation, plans, and guidelines that legally enshrine and promote gender equality. This is the case in research and innovation (R\&I) as much as in other work contexts. As extensive research from the USA (Acker and Armenti, 2004; Etzkowitz et al., 2000; Ibarra et al., 2013; Winslow and Davis, 2016) and the UK (Gill, 2010; Ahmed, 2012), as well as recent comparative studies from the European Union, have shown (e.g., Murgia and Poggio, 2019), context matters for understanding the dynamics of this persistence, including in more recent and emerging employment fields such as biotechnology, health technology, and Digital Humanities (Cozzens and Thakur, 2014; Evans, 2019; Earhart et al., 2020; Gkiouleka et al., 2018; Griffin, 2019). These fields provide useful examples of the gendered R\&I career struggles that are typical under the current regime of academic capitalism (Slaughter and Leslie, 1997; Slaughter et al., 2004).

In this article, we explore the persistence of gender inequalities in R\&I as an employment arena, specifically their occurrence in academia throughout three Nordic countries: Finland, Sweden, and Norway. These Nordic countries are of particular interest here because they have consistently topped the charts in both gender equality and innovation. ${ }^{1}$ This article focuses particularly on relatively new and emerging employment fields in academia (biotechnology, health technology, and Digital Humanities) and women's careers in these work contexts. Our key research question is: in these ostensibly egalitarian countries, how are women's careers in R\&I impacted by persisting inequalities? By exploring these careers, we purposively adopt a qualitative, bottom-up approach, drawing on two sets of interviews conducted in the period 2017 to 2020. Such data provides the rich, in-depth reflections that speak to the mundane everyday experiences of women working in R\&I, in ways that cannot be captured by statistics and which provide some unexpected answers regarding the persistence of Nordic R\&I workplace inequalities. We, therefore, contribute to a wider understanding of how specific everyday experiences of women working in R\&I articulate persistent gender inequalities in academe.

Theoretically, we draw upon Charles Tilly's (1998) Durable Inequality to explore the salience (for the Nordic R\&I context) of the four mechanisms perpetuating inequality that Tilly identifies - exploitation, opportunity hoarding, emulation, and adaptation. To examine this, we map these mechanisms onto the 4-stage researcher career model that governs the Nordic countries (Scholz et al., 2009: 9): doctoral student; postdoctoral researcher;

${ }^{1}$ See https:// eige.europa.eu/gender-equality-index/2019, European Innovation Scoreboard, 2019 (accessed 10 July 2020 ). 
researcher/university lecturer; and research director/full professor. We contribute to the current knowledge of gender inequalities in academe by arguing firstly, that a complex interplay of factors produces the gender inequalities that continue to prevail in Nordic R\&I. Secondly, we argue that academic institutions and work communities both co-produce and reinforce these inequalities. Thirdly, we claim that these are particularly evident in unquestioned mundane everyday practices.

We begin with a literature review about gender in R\&I, discussing Tilly's theorisation of durable inequalities before outlining the specificities of the 4-stage researcher career model of the Nordic countries. We detail our research methods and materials, then discuss our findings in the light of Tilly's inequality mechanisms. Here, we contribute to our understanding of gender inequalities in academe by suggesting that somewhat different gender inequalities are at play at each of the career stages, and that their interplay contributes to the durable inequalities that accompany women's research careers in the Nordic countries.

\section{GENDER IN R\&I: A LITERATURE REVIEW}

Gendered careers in R\&I take many different forms and are well documented (e.g. Andersson et al., 2012; Lindberg, 2012). Commonly asserting binary differences between women and men, this research covers a broad range of processes, practices, products, and actors, revealing the gendered differentials at play in hiring, promotion, pay, research funding, end-user imaginaries, the conception of innovations, and their execution, and many other dimensions, as described by Joan Acker (2006) in her work on organisations as 'inequality regimes'. Metaphors, such as the glass ceiling, the leaky pipeline, and scissors, have been used to describe the diminishing numbers of women involved in R\&I higher up the organisational ladder (Dubois-Shaik et al., 2019). The underlying message is always the same; R\&I is associated with the masculine (Ahl, 2004; Andersson et al., 2012; Lindberg, 2012) due to the fact that men typically dominate these domains. Further, innovation is invested with notions of creativity, competitiveness, the aggression to pursue one's aims, and so forth, which are seen culturally as masculine qualities (Berglund and Granat Thorslund, 2012). This puts women at an automatic disadvantage, resulting in them being side-lined, not promoted, not supported, getting less funding, and having to perform more strenuously to gain recognition (Dubois-Shaik et al., 2019). This disadvantage is even greater for women of colour in STEM fields (Williams et al., 2016).

One might expect this situation to be different in countries that top the gender equality charts, such as the Nordic countries. But this, as we shall show, is not the case. Statistics from the USA and Europe indicate a gender paradox, namely: women remain under-represented in the top positions of R\&I, in many STEM fields, and private sector R\&I, although they represent around $50 \%$ of $\mathrm{PhD}$ students overall - though not in STEM subjects (SHE Figures, 2018: 23, 26). Significant research has been undertaken regarding the mechanisms that produce this paradox at the level of individuals, organisations and institutions, cultures and societies, and a combination of these levels (e.g., Caprile et al., 2012; Murgia and Poggio, 2019; Gill and Donaghue, 2016). The attitudes and aspirations of individual women have received broad attention (e.g., in European Conferences on Gender Equality in Higher Education, in the Journal of Gender, Science and Technology). Many studies focus on top positions (professorships) or the STEM fields, investigating why women do not enter or stay within them, exploring the gendering of recruitment practices (Nielsen, 2016; Van den Brink and Benschop, 2012), excellence, talent, and relative advantages (Salminen Karlsson et al., 2018), networking that influences promotion (Berger et al., 2015; Henry et al., 2020; Nielsen, 2016; Vehviläinen et al., 2010), old and new masculinity cultures in R\&I (Lund et al., 2019; Pecis and Priola, 2019), struggles to combine R\&I work and care responsibilities (Acker and Armenti, 2004; Thun, 2020), and STEM fields and institutions (Branch, 2016; Rolin and Vainio, 2011; Seron et al., 2018; Tiainen and Berki, 2019). Researchers have further analysed gendered practices in R\&I in terms of societal and institutional discourses of gender equality (Thun, 2020; Lätti, 2017), and from the perspective of the marketisation of R\&I in neoliberal ideologies and economies, which emphasises the individuality of careers (Blackmore and Sawers, 2015; Gill, 2010; Gill and Donaghue, 2016; Morley and Crossourd, 2016). All these studies demonstrate how persistent gendered inequalities in R\&I cause disadvantages for women. These studies frequently focus on the formal processes associated with entering and progressing in R\&I. However, as Herschberg et al. (2019) and Husu (2001a; 2001b; 2005) indicate (as we shall demonstrate below), these gendered processes are exercised significantly through informal processes and practices which intersect with and cut across formal ones.

The gendering of R\&I is shaped within the formal and informal practices of work organisations and communities of practice (Acker, 2006). The prevailing gender segregation of R\&I institutions itself structures those organisations. Work communities in R\&I vary from being male-dominated (more than $60 \%$ men, found especially in many STEM fields) to female-dominated (more than 60\% women, for example in pharmaceutical sector) and mixed-gender communities (for example in the social sciences) (SHE Figures, 2018: 53, 78, 83). The first and last communities of practice often have male-dominated leadership. There is more gender inequality in male-dominated 
STEM communities than in mixed-gender and female-dominated communities in European countries; similar inequalities occur in US male-dominated R\&I organisations (Case and Richley, 2013).

Gendered disadvantage is mainly investigated through the concept of gender inequality (e.g., Van den Brink and Benschop, 2012) or in terms of gender discrimination. Liisa Husu's (2001a; 2001b) study of Finnish universities observed direct discrimination in breach of the Gender Equality Act, and subtle discrimination in mundane practices that were not always recognised or directly labelled as such. Husu acknowledges that many of the discriminatory patterns she identifies were already highlighted in research in the 1980s (Luukkonen-Gronow and Stolte-Heiskanen, 1983). The implication is that the reality of gendered discrimination has not improved very much, and that subtle forms of discrimination can cause as much harm as direct ones (Jones et al., 2017). Jones et al. and Winslow and Davis (2016) also raise the issue of cumulative disadvantage (see Merton, 1988: 606). They researched women in the US tenure-track system to explore how gender inequality manifests itself across the academic life course. Family and care responsibilities were implicated in this disadvantage (see also Acker and Armenti, 2004).

Neoliberalism and the marketisation of universities (Gill, 2010; Gill and Donaghue, 2016) have led to increasing job precarity through the casualisation of research labour, including a rise in fixed-term contracts in R\&I, affecting female researchers in particular (Le Feuvre et al., 2019). LeFeuvre et al. examine different forms of R\&I labour markets in relation to early career arrangements and gender equality in six European countries, not including Finland, Norway, or Sweden, the countries we focus on in this article. Although gender inequalities in R\&I occur in all six countries and manifest similar gendered subtle discriminatory patterns, for example in recruitment (Herschberg et al., 2019) and in combining family and work in 'greedy' R\&I institutions (Krilic et al., 2019), they argue that it is the local institutional contexts that primarily matter in issues of gender inequality in R\&I (see also Gatrell, 2011; Lund et al., 2019; Pecis, 2016). Our study thus contributes to knowledge about gender and R\&I careers by focusing on the institutional contexts prevailing in the Nordic countries.

European and USA R\&I institutions have promoted policies directed at achieving gender equality for decades. Gender equality is integrated into the research frameworks of the European Commission; it is mainstreamed in the policies and even practices in many European universities. For example, all Nordic university employees are covered by gender equality plans (SHE Figures, 2018). Herschberg et al. (2019) note that all members of the recruitment committees in the six European countries they interviewed supported the idea of gender equality in academia on a general level (although failing to do so in practice). There is a well-established discrepancy between the supposedly favourable policies of equality and diversity, and their actual implementation or achievement (Ahmed, 2012; Callerstig, 2014; Mazur, 2017). The Nordic countries have a further, specific problem: they top global gender equality indexes (Gender Equality Index 2019), being described as 'near nirvanas' of gender equality (cf. Lister, 2009). But gender inequalities prevail in R\&I throughout these countries, as they do in many others (Holth et al., 2017). However, the high international ranking of the Nordic countries on gender equality indexes makes such inequalities, especially the structural elements and practices that foster them, harder to be recognised and articulated (Thun, 2020; Ylöstalo, 2016). The Nordic version of the gender paradox in R\&I (with the underrepresentation of women in top R\&I positions and STEM fields) has to develop a gender equality that supposedly already exists (Martinsson et al., 2016: 1).

In considering the connections between R\&I labour markets, career path systems, and gender inequality in R\&I, one has to remember that the Nordic academic career path models differ from those in Europe and the USA (Le Feuvre et al., 2019) — although the Anglo-American tenure-track system is slowly becoming more common in certain Nordic countries. However, overall researcher career paths in the Nordic countries remain closer to the European Science Foundation 4-stage model. As our data consists of biographical researcher career path accounts and the interviews were almost exclusively conducted with stage 2 to 4 R\&I personnel, we, like Winslow and Davis (2016), examine gender struggles throughout the research career stages, but for the Nordic context.

To change male-dominated or masculine structures and cultures (Burke and Major, 2014), we need to understand the underlying assumptions and practices that sustain them. Hence, we utilise Charles Tilly's (1998) conceptualisation of inequality mechanisms to explore women's R\&I careers in the Nordic countries. This conceptualisation speaks to our understanding of the constructedness of gendered career opportunities (Burr, 2015). Women's careers are often more disrupted than men's, particularly in the new technology-driven knowledge economies where linear careers have given way to increasingly flexible and parallel careers (Allen et al., 2016; Biese, 2017). These have specific implications for women's careers. What happens to women's careers specifically in the Nordic countries, therefore, remains both a timely and an urgent research question.

\section{DURABLE INEQUALITY}

Since we are concerned with the persistent inequalities that frame women's experiences of working in Nordic R\&I, we utilise Charles Tilly's (1998) Durable Inequality to explore what explanatory power Tilly's inequality

(C) 2021 by Author/s 
mechanisms have in this context. His volume takes as its starting point the notion that 'socially organized systems of distinction' such as class, gender and race operate on the basis of categorical pairs, such as female/male, old/young, and other such binaries (Tilly, 1998: 4). These circulate widely inside and outside of organisations, used by those who 'control access to value-producing resources [to] solve pressing organizational problems' such as who to give research funding to when resources are circumscribed, or whom to promote when only one professorship is available (Tilly, 1998: 8). Tilly's argument is that durable inequality 'depends heavily on the institutionalization of categorical pairs' and on their combination with hierarchies (1998, 8: 100). Durable inequality thus rests upon distinctions affected by categorisations that asymmetrically enshrine differences. On the basis of these asymmetrical differentiations, all manner of other differences are legitimated; for instance, differences in status or income, or access to networks and funding. Organisations incorporate categorical distinctions that circulate more broadly in society because this lowers their transaction costs. Categorical inequalities do boundary work in that they create distinctions of inclusion and exclusion. Change occurs when the benefit of that change outweighs the costs of staying within established patterns of inequality. ${ }^{2}$

Tilly identifies four mechanisms through which durable inequalities are generated and maintained exploitation, opportunity hoarding, emulation, and adaptation. Exploitation occurs when people command resources from which they benefit whilst excluding those who help to produce those resources (Tilly, 1998: 10). One example of this could be senior staff getting junior staff to conduct research on which the former then base their publications without a proper acknowledgement of the latter's work. Opportunity hoarding involves people of one categorically bounded network having access to resources that support their network, for example men's use of 'old boys' networks' to access jobs (Tilly, 1998: 10). Emulation refers to the copying of existing organisational and structural models, meaning that communities replicate certain patterns across different organisational structures. In many university contexts, for example, it is only departments (not centres or other less typical institutional formations) that have representation on faculty and other important decision-making boards. Finally, adaptation refers to 'the elaboration of daily routines... on the basis of categorically unequal structures' (Tilly, 1998: 10). Adaptation, in some respects, follows on from emulation - for instance, in the unequal treatment of women compared to their male counterparts, regardless of when they come into the university or at what level. Our intention in this article is to analyse how these four mechanisms play out in the narratives of our informants when analysing persistent inequalities in Nordic R\&I.

Although we are drawing on Tilly's work, we are well aware of the criticisms it has attracted (e.g., Mann, 1999; Morris, 2000), in particular Barbara Laslett's (2000: 476) contention that 'in Tilly's exclusive emphasis on organizations and on categorical relationships, the actor - the human agent - is lost from sight' However, we understand organisations as bounded but porous entities. They involve human actors through whom direct and indirect exchanges between organisation-extrinsic and organisation-intrinsic worlds take place in complex and nonlinear ways. Indeed, we approach the R\&I organisations that we investigate, universities, and the private sector, from the perspective of those human agents. In this we do not posit organisations and human agents as discrete and/or incommensurate entities but rather view them as mutually constitutive in respect of their practices. Tilly's work is valuable for us here because it focuses on an issue that preoccupies us - persistent gender inequalities and centres on organisations, which for our purposes are R\&I institutions. We also find his relational approach (Diani, 2007; Tilly, 2001; Tomaskovic-Devey, 2014; Tomaskovic-Devey et al., 2009) useful as it gestures towards the importance of context (understood as both human and non-human) and structure whilst refusing the individualising logics of contemporary socio-political cultures. Such cultures permeate organisations so thoroughly that even in the face of blatant structural inequalities such as wage differentials, these are not attributed to structural issues requiring collective action but to individual failings (Orgad, 2019). An example of this is Seron et al.'s (2018) account of women's interpretation of their status within the engineering profession and the attrition rates of women on engineering degree courses. Despite fully recognising their unequal treatment and status, these women had internalised two core values of the engineering culture, meritocracy and individualism, so strongly that they were unable to mount anything but self-criticism against 'the gendered consequences of engineering professional hegemony' (Seron et al., 2018: 158). The detrimental effects of this internalisation of individualising discourses of merit, excellence, and choice have also been explored elsewhere (Beddoes and Pawley, 2014; Canetto et al., 2017; Sørensen, 2017). Against such individualising, we welcome Tilly's focus on systemic and structural inequality mechanisms as a necessary corrective to contemporary work cultures. We now outline the Nordic 4-stage career model.

\footnotetext{
${ }^{2}$ Laslett (2000: 476) states that Tilly is 'unable to address the question of how inequalities can be ameliorated' but he at least sketches the conditions under which change might occur.
} 


\section{THE 4-STAGE RESEARCH CAREER MODEL: NORDIC VARIATIONS ON A THEME}

In 2009 the European Science Foundation proposed a 4-stage researcher career model consisting of stage 1 (doctoral training stage), stage 2 (postdoctoral stage), stage 3 (independent researcher stage) and stage 4 (established researchers: professors, research professors, directors, senior scientists, etc.) (Scholz et al., 2009, 9). Career structures function as hierarchies of professional attainment, involving greater financial rewards, greater degrees of power (over juniors in the profession, within institutions and in the discipline) and reward as one progresses. Researcher careers in Finland, Norway, and Sweden broadly follow this model (but see Siekkinen et al., 2017). However, all three countries also exhibit complex variations on this theme. Automatic advancement from one career stage to the next does not occur; rather, at each stage individuals must apply when posts become available. The moves from stage 2 to 3, and from stage 3 to 4, are tricky. The number of professor posts is low, relatively and in absolute numbers, vacancies are rare, and women represent a minority at Grade A (professor) level (Table 1). Thus, as can be seen in other countries, many researchers with high academic competences never progress beyond stage 3 (Grade B).

Table 1. Proportion (\%) of women among academic staff by country

\begin{tabular}{lcccc}
\hline & Grade A & Grade B & Grade C & Grade D \\
\hline EU-28 & 23.7 & 40.5 & 46.4 & 46.9 \\
\hline Finland & 29.4 & 49.1 & 50.7 & 49.0 \\
\hline Norway & 27.9 & 45.6 & 49.6 & 57.1 \\
\hline Sweden & 25.4 & 45.8 & 45.7 & 49.7 \\
\hline
\end{tabular}

Source: Adapted from SHE Figures 2018, R=Table 6.1, p. 118.

The term 'grade' used in Table 1 broadly maps onto the 4-stage career model: Grade A represents full professors and Grade D people in jobs such as junior researchers who do not yet have a $\mathrm{PhD}$. Table 1 suggests that the greatest problem in women's researcher careers is the move from stage 3 (Grade B) to stage 4 (Grade A). However, as our data show, gender inequalities occur at every career stage, with serious consequences for the move from stage 3 to 4 .

The 4-stage model's specifics are somewhat different in Finland, Norway, and Sweden, especially at stages 3 and 4 (Table 2).

Table 2. 4-stage research career model in Finland, Norway and Sweden

\begin{tabular}{|c|c|c|c|}
\hline & Finland & Norway & Sweden \\
\hline Stage 1 (doctoral students) & $\begin{array}{l}\text { Nearly all on fixed-term } \\
\text { contracts. }\end{array}$ & Fixed-term contracts. & Fixed-term contracts. \\
\hline Stage 2 (postdocs) & $\begin{array}{l}\text { Nearly all on fixed-term } \\
\text { contracts, mainly external } \\
\text { funding. }\end{array}$ & $\begin{array}{l}\text { Nearly all on fixed-term } \\
\text { contracts, mainly external } \\
\text { funding. }\end{array}$ & $\begin{array}{l}\text { Nearly all on fixed-term } \\
\text { contracts, mainly external } \\
\text { funding. }\end{array}$ \\
\hline $\begin{array}{l}\text { Stage } 3 \text { (independent } \\
\text { researcher; university lecturer) }\end{array}$ & $\begin{array}{l}\text { Researchers: mostly on fixed- } \\
\text { term contracts and on external } \\
\text { funding. } \\
\text { University lecturers: either on } \\
\text { fixed-term contracts or on } \\
\text { permanent contracts. }\end{array}$ & Mostly permanent positions. & $\begin{array}{l}\text { Researchers: mostly on fixed- } \\
\text { term contracts and on external } \\
\text { funding. } \\
\text { University lecturers: either on } \\
\text { fixed-term contracts or on } \\
\text { permanent contracts. }\end{array}$ \\
\hline $\begin{array}{l}\text { Stage } 4 \text { (senior researcher, } \\
\text { professor, director etc.) }\end{array}$ & $75 \%$ on permanent contracts. & Mostly permanent positions. & $\begin{array}{l}\text { Mostly permanent positions; mix } \\
\text { of internal and external funding. }\end{array}$ \\
\hline
\end{tabular}

As Table 2 shows, stage 3 researcher and university lecturer positions in Finland and Sweden can be either fixed-term or permanent, whilst in Norway they are permanent (see Svalund and Berglund, 2018, for a discussion of fixed-term contracts and their impacts in Sweden and Norway; also on Finland Aarnikoivu et al., 2019). Lecturer positions tend to be permanent, teaching-centred and dependent on internal funding associated with student numbers. Research positions are often fixed-term and externally funded. In Finland and Sweden, the move from stage 3 to stage 4 frequently involves a move from external funding to (partial) university funding (one's own salary comes fully or partially from internal university funding, but the research group - if the professor runs such a group - would still require external funding). Many researchers become stuck here, experiencing, as we shall discuss, gendered injustices at the point when they should move from one stage to the next. 


\section{RESEARCH METHODS: DATA COLLECTION, PARTICIPANTS, AND DATA ANALYSIS}

We draw on qualitative research conducted in 2017-2020 to explore why R\&I has not followed the general trend in the Nordic countries towards greater gender equality. We discuss the gendered experiential actualities that women and men pursuing careers in R\&I reported encountering in their everyday working lives. In doing this, our intention is to start from the data in a qualitative, bottom-up approach as opposed to seeking to provide objective comparisons, either between women and men, or across countries. The two data sets offer rich information in this respect. Our research involved semi-structured, one-on-one interviews with women and men in R\&I in Sweden, Finland, and Norway. However, in this article we focus only the women's reported experiences. The questions centred on six topics: 1) their current post; 2) their employment histories; 3) education, specifically technology training; 4) experiences of being mentored; 5) experiences of the role of gender; 6) ways of updating oneself professionally (i.e. how informants learnt about developments in their field). As the Nordic countries have relatively few higher education institutions, and so as to maintain confidentiality, participants' institutions are not named here. ${ }^{3}$ All except one participant in both data sets were white. This reflects the dominance of white people in Nordic academe, but also the colonial and immigration histories of the Nordic countries. ${ }^{4}$ For the purposes of this article, we draw on two sets of interview data. The first set involved 30 Digital Humanities (DH) practitioners in higher education institutions and officers responsible for DH research programmes in Sweden, Finland, and Norway (16 women and 14 men). Their ages ranged from 29 to 62. Participants were purposively selected through searching the online staff lists on DH websites of five universities in each of the three selected countries, and through searching research funder websites for staff working in funded DH projects. Nine of the DH participants were professors (stage 4), 11 were researchers or university lecturers (stage 3), one was a postdoc (stage 2) and two were $\mathrm{PhDs}$ (stage 1). Seven interviewees were technicians, programmers, or similar. The professors had, of course, gone through the previous three stages and talked eloquently about their experiences at those stages. The interviews lasted between 43 and 70 minutes. In addition to the shared six topics, the interviews dealt with technology acceptance within the family and $\mathrm{DH}$ as an academic discipline.

The second set of data consisted of 30 career interviews with women working in R\&I in health technology fields in Finland, conducted in 2018-2020. The interviewees were found using the snowball technique. All but two had PhDs. Many had multidisciplinary backgrounds, and had undertaken doctoral studies and/or postdoc research in emerging multidisciplinary research areas. The interviewees' ages ranged from 25 to 62. Five were professors (stage 4), nine were senior researchers (stage 3) at universities and research institutes, and three were experts in the Finnish offices of large international firms. Three women had expert jobs in public-sector organisations and seven worked in managerial positions in small Finnish firms. One was a doctoral student and two had started an educational programme in a new field. All but one of the 30 women were interviewed face-to face in Finnish. ${ }^{5}$ The interviews took 1-2 hours. They were conducted and analysed in Finnish, then translated into English for the purposes of this article. In addition to the shared six topics, they covered the theme of the work-life balance.

All interviews were analysed using thematic analysis (Braun and Clarke, 2006). This means that intense, repeat readings of each transcribed interview took place to identify core themes that emerged from the data. These identified themes included 'career blocking,' 'derogating women,' 'differences between women and men,' 'employment through networks,' 'exploitation,' and 'female mentors'. They were also re-read separately, utilising Tilly's four mechanisms. The combination of these two processes led to thematic nodes according to certain core themes, including recruitment experiences, experiences of discrimination, work cultures, and employment histories. Overall, we identified four key practices which produced gendered inequality effects on R\&I researcher careers: supervision, recruitment, seeking external funding, and networking. These practices articulated forms of exploitation, opportunity hoarding, emulation, and adaptation. They came into play in different ways throughout the four different career stages, as we discuss below.

\footnotetext{
${ }^{3}$ Sweden has 24 HEs able to award third-cycle qualifications (http://english.uka.se/facts-about-higher-education/highereducation-institutions-heis/list-of-higher-education-institutions-in-sweden.html); Finland has 14 universities (http://www.studyinfinland.fi/instancedata/prime_product_julkaisu/cimo/embeds/studyinfinlandwwwstructure/100601_ Higher_Education_Finland_2016_2017.pdf); and Norway has 9 universities (https://www.studyinnorway.no/study-innorway/higher-education-system) - all accessed 19 June 2018.

${ }^{4}$ There is no space to explore this further here, but the Nordic countries have had relatively 'late' immigration, from the 1970 s, mainly from the 1990s onwards (see Pred, 2000).

5 The interviews were carried out by the Nordwit researchers Tïna Suopajärvi and Minna Leinonen.
} 


\section{FINDINGS}

Charles Tilly's (1998) four inequality-producing mechanisms - exploitation, opportunity hoarding, emulation, and adaptation - operate at societal, institutional and individual levels in the Nordic countries, but in diverse ways and to different degrees. Tilly argues that 'exploitation and opportunity hoarding favour the installation of categorical inequality, while emulation and adaptation generalize its influence' (1998: 10). In the following we will show that exploitation and opportunity hoarding in various forms were by far the most common mechanisms deployed in R\&I institutions. Intra-organisational inequalities come into being through 'emulation, the copying of established organisational models and/or the transplanting of existing social relations from one setting to another' (Tilly, 1998: 10)

\section{Emulation and Adaptation in R\&I Organisations}

In the Nordic countries, welfare practices and equality measures have been spread throughout society through emulation. This emulation might suggest that gender equality may readily emerge in R\&I as well. But, this rests on the erroneous assumption that the Nordic countries are largely gender equal (Martinsson et al., 2016). Equality before the law is extensively established in the Nordic countries (for example in granting generous parental leave of up to a year). However, this does not mean equality in practice. Thus, although de jure men in all Nordic countries can take parental leave, de facto only a limited percentage do so, and mostly for a limited period of time (Cederström, 2019).

Nonetheless, the Nordic countries are strongly associated with a public discourse of equality and related institutionalised policies (see Silius, 2002; Gordon, 2002), including institutional gender mainstreaming and gender equality plans which cover practically all staff members in R\&I organisations (SHE Figures, Table 5.8). These constitute, in Tilly's terms, adaptations or 'the elaboration of daily routines ... and information gathering... on the basis of categorically unequal structures' (Tilly, 1998: 10). In other words, R\&I organisations adapt to broader societal requirements to implement gender equality by creating gender equality plans. For example, these frequently involve gathering data regarding unequal structures such as salary information disaggregated by gender. R\&I institutions then produce gender equality plans, but these vary widely and are often vague (see Lätti, 2017; Nielsen, 2014). Many employees do not know about these equality plans (e.g., Gender Equality Barometer 2018: 59), and they are rarely invoked in any way. ${ }^{6}$ Science funding agencies, including European ones, have installed gender equality measures (such as aiming to have equal numbers of women and men on boards and in international reviews) but either content themselves with a 40/60 split (or thereabouts), or do not have any form of sanction if those measures are not adhered to (Husu and Cheveigné, 2010). They promote a myth of equality (see Martinsson et al., 2016) which silences issues of inequality, making claims based on actual experiences of inequality difficult to raise and pursue.

In On Being Included: Racism and Diversity in Institutional Life, Sara Ahmed (2012) discusses the ways in which equality measures, policies, and the public rhetoric on equality can act as non-performative performatives, meaning that the changes these measures and policies are meant to bring about are assumed to have been effected by the very fact of having a policy. In other words: nothing is done because a policy is in place. This then becomes an empty signifier. One might argue that many equality measures constitute empty signifiers of sorts. This is one important reason why gender discrimination in the Nordic countries persists, including within R\&I (Callerstig, 2014). The gap between policy and practice, between ideal and on-the-ground experience, and between the formal and the informal is significant (Mazur, 2017).

\section{Opportunity Hoarding and Exploitation at Career Stage $1(\mathrm{PhD})$}

At stage $1(\mathrm{PhD})$ five issues crystalised the gendered inequalities experienced by our interviewees: the quality of the supervision and mentoring received, sexual harassment, being side-lined in terms of their work or in research project participation, and not being given statutory rights, in particular parental leave. The quality of supervision and mentoring was crucial for $\mathrm{PhDs}$ to complete their thesis successfully but, more importantly perhaps, for them to be able to position themselves effectively when entering the next career stage - becoming a postdoc. As Pauliina, a former Finnish $\mathrm{PhD}$, described it:

I never had the feeling that my research really started to fly. I had always been very good at school, at the top until the Masters. Really good. If I had had sophisticated supervision, I could have become an

\footnotetext{
6 The Swedish HE system has a number of equality mechanisms that the institutions invoke (see https://eige.europa.eu/gender-mainstreaming/toolkits/gear/legislative-policy-backgrounds/sweden) but this does not detract from persistent gendered inequalities within the system, for example around the pay gap.
}

(C) 2021 by Author/s 
Academy[]]-funded researcher, but as it did not happen, I experienced continuous difficulties, sometimes also failures. It, of course, was eating away my motivation to stay in the field.

Poor $\mathrm{PhD}$ supervision impacted on the interviewees' ability to move from stage 1 to stage 2 . This move requires the competence to write successful grant applications, meaning PhDs who had not been mentored in this skill found it hard to compete. As Marika, at the time of the interview working in a private company in Finland, said: 'I continued with the same distress, how can I get the application done, I thought that I should have done the Academy application... despair started to emerge.' This problem was exacerbated if their supervisor had not helped the $\mathrm{PhD}$ to establish relevant networks since such postdoc applications often depend on inter/national collaborations.

Whilst the failure to supervise PhDs effectively might, in Tilly's terms, be considered a form of opportunity hoarding in that those who were well supervised were at a significant advantage over those who were not, straightforward exploitation was mainly described in terms of sexual harassment, as well as in terms of being made to do all the work for a professor who then took the credit. Among our interviewees, several reported experiences of (sexual) harassment, bullying, and forms of professional exclusion they had experienced from senior colleagues. Such experiences mostly belonged to the first and sometimes the second stage of researchers' careers. Bullying and sexual harassment by male professors - only in one case by a female professor - were raised by a distinct minority of former PhDs. One Finnish interviewee, Susanna, said:

I lasted longer than the others [other female PhDs], but still he was kind of, I guess in retrospect I would call him sociopath, but I didn't understand it then because I thought this is the way that academia works, that somebody is telling you how shit your work is. So he had his male protégés, so big impact there.

This interviewee brings up a significant point: normally one only undertakes a $\mathrm{PhD}$ once, so it is difficult to know what is acceptable workplace behaviour and what is not. In countries with small $\mathrm{PhD}$ cohorts, such as the Nordic ones, this can be a particular problem because there are few points of comparison. Although this interviewee, like another one, had not taken this bullying lightly, she said that 'when I left university after my postdoc I was so disillusioned.' Such disillusionment was not uncommon among our female interviewees. Britta (Swedish, director of studies) effectively had her research closed down by the leading male professor in her lab. 'Closed down' here means that she was prevented from continuing her research. This man reportedly 'didn't believe in our results... it was like someone was in the room who made decisions that we didn't know, who we were fighting against...' He had undermined Britta's attempts to gain new research monies. This eventually led to her leaving the DH field. Here, the categorical co-pairing, or imbrication, of gender with status and professional knowhow (male-female, senior-junior, experienced-inexperienced) facilitated behaviour that allowed no room for negotiation for the woman in question.

Women such as Britta were likely not to have developed networks in their field. This created professional isolation which then made it easy for them to be side-lined by senior men. Anna, a DH researcher working in Sweden, spoke of her experiences as a $\mathrm{PhD}$ student in a $\mathrm{DH}$ centre, led by a male professor who had silenced young women: 'we would find it quite difficult to say something, to know where I can say things'. She was fully aware of the gendered hierarchies that prevailed, and said of the two senior males in the centre: 'it was quite clear that... I was not someone they would prioritise.' Experiences of overtly gendered discrimination, exploitation and opportunity hoarding (in favour of males) in the early stages of one's career were thus not uncommon, and could potentially lead to some women's premature abandonment of their research careers, or to them seeking employment in the private R\&I sector.

\section{Women's Experiences of Harassment: Exploitation and its Effects}

Women's experiences of harassment in R\&I took different forms among our interviewees. Sexual harassment as such was not much discussed. Importantly, neither women nor men reported being sexually harassed by women. Nonetheless, quite a few interviewees knew about male-on-female sexual harassment in their research groups and networks, or talked about avoiding actual harassment; as did Sari, a senior researcher in Finland:

A couple of times I've been in a situation that an older male professor has suggested, and then I've seen that that's a kind of dangerous situation, that I don't want to end up here, ... afterwards it's turned out that they've ... given the position to someone else.

Thus, actual harassment or even, as noted here, its avoidance, influenced individual careers, the mundane research work, and the giving and taking of work opportunities. Failure to succumb to harassment would lead to

\footnotetext{
7 'Academy' here and elsewhere in this text refers to the Academy of Finland, the equivalent of a national research council, and the key research funding body in Finland.
}

$8 / 17$

(C) 2021 by Author/s 
professional exclusion and side-lining, where women found themselves disregarded by the senior males (often professors) who called the shots. Harriet (Finnish, associate professor) talked about the power play her male supervisor engaged in. Despite having also encountered men who 'systematically pushed [her] forward,' her experience in academe was as follows:

the faculty is, professors are almost all male, when I talk about them, they are all men. And the women who are among them, they start behaving like them also. So it's very kind of male... PhD men [male doctoral students] tend to have better academic careers than women, systematically, if you look at the numbers.

Harriet describes not just a masculinist culture in academe, but also how female professors emulate this culture as part of an adaptation to their position.

\section{Opportunity Hoarding at Career Stages 2 and 3 (Postdocs, Researchers): The Vicissitudes of Informal Recruitment and Other Processes}

A masculinist culture became particularly prominent at the point of recruitment to research career stages 2 and 3. Here we found strong consistent evidence of opportunity hoarding in favour of men through informal processes, even when formal processes were engaged with. Formal recruitment processes were, in the case of men, effectively disregarded in favour of informal ones that completely bypassed the formal ones. A common experience among the men we interviewed was to be 'handpicked,' as respondent Sven (Swedish, director of DH lab) stated, meaning that they were invited into posts at DH centres or labs by more senior staff, usually males, who hired them even if they had no direct qualifications for such jobs. This constitutes obvious opportunity hoarding: senior men assisting junior men into jobs. Anders, a Finnish digital media scholar, said: 'I've been, so to say, actively recruited to quite a few of the ... positions I've had.' These cases of opportunity hoarding among male researchers were very common in our sample (also, tellingly, a website discussing researcher careers in Norway unambiguously states: 'many jobs are offered through personal contacts, even if they already have been or plan to be advertised'8 $)$. Some female interviewees working in health technology also reported being recruited through networks, usually by other women. Health technology has large numbers of women so opportunity hoarding among women was possible there. Female DH interviewees did not report such experiences.

If women did manage to move into stage 2 and 3 positions, they had to contend with three issues that dogged their progress: getting external funding, not just for themselves but for the research groups they were expected to establish to move into stage 3; lack of control over their research groups and projects; and issues around parenthood. These issues could become intertwined in complex and opaque ways. Helena, a Finnish researcher working in a university, for example, described this as follows:

After having children, the support that I had had started somehow to diminish. I can't say, is it because I had children or because we started to approach the end of the funding period which meant the start of the survival game. ... They transferred the research lab that I had established with the funding I had secured to another [male] researcher ... Soon after, he was appointed as a professor.

Helena was unable to get any explanation for the process that had occurred:

I never got any answer, and I've spoken to several professors, even confidentially... this is very typical in the academic world, that one never actually finds out...

Such gender discrimination leaves female researchers in a quandary as to what exactly happened, unable to get redress. Women with this experience had a clear sense of gender discrimination and understood it as opportunity hoarding among men, but found it impossible to challenge or resist. Johanna, a Swedish associate professor, for example, described how jobs had been arranged for men by their 'mates': 'they are part of this circle of friends and it makes sense that this person is a professor there, supporting those other friends who are men.' The very fact that this 'makes sense' to Johanna points to the logics of informal unequal arrangements that prevail here, and to a known acceptance of this. These arrangements were, in the Finnish context, exacerbated by the decline in research funding from 2008 onwards (OECD, 2017: 110, 114) which has shaped that R\&I context. They point to the persistence of homosocial networks or 'old boys' networks' in academe (Coate and Howson, 2016; Rose, 1989; Van den Brink \& Benschop, 2014).

8 At https://www.lifeinnorway.net/researcher-jobs-in-norway/ (accessed 16 May 2020).

(C) 2021 by Author/s 


\section{Opportunity Hoarding and Parenthood}

In the Nordic countries, the drive to promote equality in the workplace has been one factor contributing to the provision of generous public childcare by international standards. But parenthood still works to the detriment of women, since despite the fact of such childcare and of the availability of parental leave for childcare (see also Edlund and Öun, 2016), only a minority of men take such leave and for very limited periods of time (NIKK, 2019: n.p.). This can retard women's careers. Among the women working in bio- and health technology it was evident that women in couples where both partners were equally involved in the childcare provision, had a greater ability to pursue their careers. This was also very clearly coupled with men having a stable, predictable work life with fixed hours, the ability to work from home, and taking a much greater share of the household work. As one Finnish biotech interviewee, Emilia, said: 'Luckily my husband can work from home a lot, that's how it usually goes if a kid is sick or something, my husband works remotely from home then.' Public childcare hours are fixed, even in the Nordic countries, so that the expansion of work beyond conventional working hours is often an issue. The continuing assumption and practice of women as carers produces specific difficulties in the context of R\&I work where expectations of flexible hours (= expansion of working time), project and deadline cultures, and the still limited involvement of men in care produce unfavourable conditions for women.

\section{Adaptation and Emulation at Career Stage 4 (Professors, Senior Researchers)}

As and when women arrive at stage 4, they have worked through an extensive process of professionalisation, acculturation, selection and adaptation. The women professors in our data shared certain characteristics: they had been mentored, sometimes by other women but also by men; they had had functional roles in academe (i.e., they had been 'good citizens', see Bergeron et al., 2013); they had spent substantial time outside of academe and/or abroad, thus building up inter/national networks, and used these networks to access significant external funding at European Commission level or in other collaborations. They were, nonetheless, the exceptions to the rule.

Once at this stage, women's gender could work in their favour as they were often 'the only one' or 'the token woman' (Kanter, 1977) since there are, relatively speaking, so few female professors (Table 1, Grade A). Being the so-called token woman means that female professors get invited to participate in high-level events precisely because they are women. This might be seen as a form of inverse opportunity hoarding, in Tilly's terms, or as a form of opportunity ascription. As Marta, a Swedish DH lab director, put it: 'I don't get much sleep, because my symbol, my symbolic value is huge, right, so I am a woman, tick, and I am a woman in humanities who deals with tech, tick, so I sit on millions of committees, right? Everywhere where there is an issue of infrastructure, I am there.' Being put in this situation afforded her possibilities for intervention, which she used: 'I use the opportunity, so you know, I am given a voice and so I use [it].' But these opportunities also produced costs. The women were always in the minority. If they supported younger female staff, they also always supported fewer people than men in equivalent positions, simply because only about $30 \%$ of professors are women. Like many other interviewees', many of the female professors' work situations were split, involving half appointments in one place and half in another. This generated particular issues that they were able to overcome partly because they had PhDs and postdocs to carry out the research work they had no time for. As Nina, a professor in Linguistics in Sweden, said:

I'm supposed to be sort of professor of [subject] half of the time, and that's obviously not possible (laughs a little)... I don't know, 15\% of the time of something, it may be at night, but so, a lot of, a lot of my research gets done by proxies, through my $\mathrm{PhD}$ students and my postdocs... I was very lucky to be awarded [a large] grant... but it's now [2017], it was in 2013, and this is a bit of a, it's a sad issue because I haven't really been able to exploit that fully, I mean, under normal circumstances, if you are given a grant of that size, ... you're bought out of admin duties and so on, but because of the nature of the, you know, the directorship of the lab, that sort of hasn't been possible.

In this quote, several conflicting demands come together. This professor has obvious difficulties in conducting research because of the demands that her two main roles make on her. Her research is therefore done 'by proxies'. This she considers 'a sad issue' which points to the fact that under other circumstances she would do that work herself. Larivière (2012) indicates that PhDs in the Arts and Humanities are far less likely to contribute to publications as $\mathrm{PhDs}$, compared to those in fields such as medicine or the natural sciences. In other words, PhDs in the Arts and Humanities are not as commonly involved in research collaborations with their professors as PhDs in some other fields. However, this professor could only get her research done at all if she asked more junior staff to take it on.

Nina, the Swedish female professor cited above, was unable to make use of a significant grant because she was mired in two major roles - being a good university citizen - which curtailed her research opportunities. Her representation of this situation reveals an adaptation to a situation where professors, especially female professors, accommodate unreasonable work conditions and acquiesce to their exploitation. This, in turn, exploits younger 
staff (docs, postdocs) who can end up doing the research work, or other academic help, for them, as Sarah Wall (2008) also points out. Interestingly, however, this was a complaint usually levelled at male professors rather than female ones. As Anna, a female lecturer in Sweden, angrily reflecting on her time as a PhD student, said: 'organising educational programs with men has been the same... I did ALL the donkey work, and that makes sense because I was younger, I guess. But there comes a time in which you actually want to ... say, "I'm not gonna sit and write this for you." Unlike some of the high-flying women in Orgad's (2019) research, for example, who left their careers because of the unreasonable work-life demands placed upon them and on their partners but read their decision in terms of personal pathology rather than structural inequalities, Anna was very aware of the gender injustices that accompanied her situation. She maintained that her best projects had been with women because 'there was a clear division of labour. Plain and simple. That's not always the case with men. Especially if the man is... higher in sort of hierarchy. They dump on you....' In the interplay between seniority and gender, unequal treatment occurred.

\section{DISCUSSION}

Tilly's inequality-producing mechanisms, especially opportunity hoarding and exploitation, dominated the durable inequality experiences which our interviewees reported at all researcher career stages. Opportunity hoarding and exploitation were evident throughout the R\&I structures, at institutional as well as individual levels, as Murgia and Poggio's work (2019) also suggests, though they do not name it in such terms. One might argue that the current academic system which requires researchers to give their all, including in precarious conditions where the notion of career progression is a process of gradual funnelling out, is itself highly exploitative, in particular at stage 3 where female researchers might acquire competitive funding and build a research group, only to see these given to other male researchers without explanation or redress — as was the case with several of our interviewees. The problematics of how institutions and individuals respond to experiences of unequal treatment in R\&I requires more research. Much of the rest of our interviewees' on-the-ground experience showed a high degree of acceptance of practices that directly contravened equal opportunities legislation, including in the context of recruitment, where parallel worlds opened up as opportunity hoarding reigned, even when formal processes were undertaken. Our findings in this respect contribute to Husu's (2001a; 2001b; 2005) in pointing to unequal treatment occurring not within but outside of or in parallel to a formal process. All of this suggests that, without rooting out such practices, tinkering with formal processes to achieve greater equality will at best have limited effects.

Exploitation and opportunity hoarding became evident in how the supervision and mentoring of $\mathrm{PhDs}$ was conducted, which either enabled $\mathrm{PhDs}$ to take the next step in their career through proper professional preparation, including how to write effective grant proposals or, on the contrary, as happened to our female interviewees, served to retard their competences, undermine their academic confidence, and to side-line them. It continued in the recruitment practices through stages 2 and 3, and was evident in how researchers' achievements (such as gaining funding and building research groups) were dealt with in obviously gendered ways. This also showed in matters of networking, as much literature already testifies, that women were mostly not introduced to, or have, sustained professional networks.

Once women became professors, they had been thoroughly acculturated into the mundane practices of inequality in the everyday of R\&I and were sometimes perceived as acting like men in that context. Part of this adaptation related to their position was turning their situation - often being the only woman - to their advantage. However, this also came at the considerable cost of overworking (cf. Britton, 2017: 18-20) and having too many demands made on them, factors that characterise contemporary research work cultures. This points to R\&I's and institutions' exploitative practices (Gill, 2010). Female professors talked about mentoring younger female colleagues, but since they themselves are always in a significant minority, they can achieve only a limited elevator effect through these practices.

This also means that the advantages that R\&I researchers in the Nordic countries appear to enjoy (such as generous parental leave and public childcare provision) will not, by themselves, change the durable inequalities that persist in the inequality-promoting informal practices found within R\&I organisations. Overall, gender equality in the Nordic R\&I emerges as a field of continuing struggle, advocated as an ideal but not enacted in practice in the ways one might hope for. The supposedly transparent and democratic work culture of the Nordic countries (Götz and Marklund, 2019) serves to contribute to the durable inequality which prevails through installing formal processes that act as non-performative performatives (Ahmed, 2012; Mazur, 2017), whilst openly practising parallel informal processes that facilitate gendered opportunity hoarding and exploitation.

In line with neoliberal ideologies, researchers at all stages adapt to the inequalities they encounter and, despite being able to name these accurately, seek their individual solutions. In the case of young female researchers this often means leaving academe after the $\mathrm{PhD}$ or postdoc stage and moving to R\&I work in the private sector, particularly if parenthood comes into play. Those who survive do so, interestingly, either by being mentored and succeeding in gaining research funding, by searching for new opportunities in other organisations, or (as was the

(C) 2021 by Author/s 
case with the women who eventually made it to the professor stage and for some at stage 3) by spending significant time abroad, building international networks that supported and sustained them in their search for recognition.

\section{CONCLUSION}

Charles Tilly's inequality mechanisms retain their salience, even in the Nordic countries in the $21^{\text {st }}$ century. Our study examined women's R\&I careers in these countries based on the four-stage career model that dominates European higher education. It shows how each of these four career stages has certain specificities regarding the persistent gender inequalities that accompany them. Altogether it is clear that a wide variety of durable gender inequalities (as documented in the existing literature on gender struggles in research and innovation) is still to be found in contemporary R\&I careers today, notably in the most gender equal parts of the world which have already advanced gender equality policies: the Nordic countries. This speaks to the limited progress that has been made regarding the elimination of these inequalities and raises questions about the salience of some of the instruments used to measure gender equality. It also suggests that topping the gender equality charts does not mean that gender equality has been achieved. Further research might be required to understand what it does mean.

Our research shows that persistent gender inequalities occur within R\&I institutions operating in a system of academic capitalism which is highly exploitative of its labour force, characterised by excessive workloads, the continuous search for competitive funding, insecure employment, and unreasonable demands of multi-tasking (Blackmore and Sawers, 2015; Gill and Donaghue, 2016; Morley and Crossourd, 2016). Given this scenario, we contribute specifically to knowledge of the gendered effects of these career conditions. We also contribute by showing that Tilly's categories for framing the persistence of gender inequalities continue to hold in contemporary R\&I in the Nordic countries, enabling us to recognise the complex dynamics of persistent gender inequalities within this structural framework. We argue that although policies for gender equality exist in all the Nordic countries and are widely emulated in Nordic R\&I, the adaptation of these into the actual practices within these institutions and organisations remains at best partial (cf. Callerstig, 2014). Instead, informal, highly gendered practices take precedence. Here, we contribute to our understanding of these informal practices by providing granular accounts of practices not commonly discussed, such as the mentoring of $\mathrm{PhDs}$ that enables them to write successful grant applications for the next stage of their career.

Van den Brink and Benschop's (2011; 2012) accounts of Dutch appointment practices regarding full professorships and Nielsen's (2016) of Danish appointment practices already pinpoint certain ways in which female applicants for these positions are either not encouraged to apply or are assessed in a discriminatory fashion. Herschberg et al. (2019) examine these processes for early R\&I careers. We, however, show that in the Nordic countries there are informal processes throughout the academic career which completely bypass the formal processes. The direct invitation of junior male scholars into posts by senior male colleagues outside of any application process is one such example. Our findings show that each of the stages has specific gendered problems, first related to supervision and harassment, and then increasingly in relation to recruitment and competitive funding processes. A culture of acquiescence accompanying unequal treatment explains how opportunity hoarding becomes possible. It is relatively easy to exercise this, relative to those in an asymmetrical power/status relation to oneself when there is little challenge to the non-observance of equality prescriptions.

A generous childcare and parental leave system is in place, which all parents in our data use. Although this does not make parenting gender equal, it could potentially have significant effects on women's opportunities in R\&I work, at least in the early career stages, if R\&I institutions themselves did not exercise informal discriminatory practices (cf. Lund et al., 2019; Thun, 2020). Childcare provision as such was not regarded as discriminatory, but R\&I institutions' decisions to move projects and research centres to other researchers, usually men, when women were on parental leave, for example, was. We had several examples of this in our study. This makes the tinkering with formal practices to promote gender equality which many studies focus on ineffective if such informal practices are not rooted out (cf. Van den Brink and Benschop, 2012).

Exploitation goes together with opportunity hoarding in R\&I. Researchers and institutions perform opportunity hoarding to secure resources and opportunities along gendered lines: men tend to favour other men by supervising and mentoring them carefully, supporting their funding applications and inviting them into their networks, whilst frequently leaving women with less supervision and support, and often also quite simply sidelining them (cf. Husu, 2001a). Gender equality and transparency in recruitment procedures were clearly violated through parallel informal processes which favour men and were widely accepted.

R\&I institutions and organisations hence play a major role in sustaining gender inequalities, and our analysis shows how this happens. If we had only looked at the SHE Figures (Table 1), valuable as they are, we would have concluded that there is a major problem and drop in women's numbers between stages 3 and 4 . Instead, we have shown that gender disadvantages start piling up from the stage 1 and continue throughout. This confirms what Liisa Husu (2001a; 2001b: 204) found for academic women in Finland already, 20 years ago. Winslow and Davis 
(2016) recognised such comparable cumulative disadvantage in women's tenure track careers in the US. Our study examines women R\&I careers in Nordic four-stage research careers which differs from the US model, and yet, shows a similar cumulative effect.

Is all this specific to the Nordic countries? To some extent. The well-established childcare and parental leave system, for example, supports women in their R\&I careers but R\&I institutions fail them. We argue that the dynamics of durable inequality that we found using Tilly's four categories, and exploitation and opportunity hoarding in particular, are a surprise in connection with the Nordic countries and hold more broadly. Much more research needs to be undertaken on the informal everyday activities that sustain gender inequality in R\&I and its specificities in different fields, including in the Nordic countries.

\section{REFERENCES}

Aarnikoivu, M., Nokkala, T., Siekkinen, T., Kuoppala, K. and Pekkola, E. (2019). Working Outside Academia? Perceptions of Early-Career, Fixed-Term Researchers on Changing Careers. European Journal of Higher Education, 9(2), 172-189. https:// doi.org/10.1080/21568235.2018.1548941

Acker, J. (2006). Inequality Regimes: Gender, Class, and Race in Organizations. Gender and Society, 20(4), 441-464. https://doi.org/10.1177/0891243206289499

Acker, S. and Armenti, C. (2004). Sleepless in Academia. Gender and Education, 16(1), 3-24. https://doi.org/10.1080/0954025032000170309

Ahl, H. J. (2004). The Scientific Reproduction of Gender Inequality: A discourse analysis of research texts on women's entrepreneurship. Stockholm: Liber.

Ahmed, S. (2012). On Being Included: Racism and diversity in institutional life. Durham: Duke University Press. https://doi.org/10.1515/9780822395324

Allen, T. D., French, K. A. and Poteet, M. L. (2016). Women and Career Advancement: Issues and Opportunities. Organizational Dynamics, 45(3), 206-216. https:// doi.org/10.1016/j.orgdyn.2016.07.006

Andersson, S., Berglund, K., Gunnarsson, E. and Sundin, E. (eds). (2012). Promoting Innovation: Policies, practices, and procedure. Stockholm: Vinnova.

Beddoes, K. and Pawley, A. L. (2014). 'Different People Have Different Priorities': Work-Family Balance, Gender, and the Discourse of Choice. Studies in Higher Education, 39(9), 1573-1585. https:// doi.org/10.1080/03075079.2013.801432

Berger, L., Benschop, Y. and van den Brink, M. (2015). Practising Gender When Networking: The Case of University-Industry Innovation Projects. Gender, Work and Organization, 22(6), 556-578. https:// doi.org/10.1111/gwao.12104

Bergeron, D. M., Shipp, A. J., Rosen, B. and Furst, S. A. (2013). Organizational Citizenship Behavior and Career Outcomes: The Cost of Being a Good Citizen. Journal of Management, 39(4), 958-984. https://doi.org/10.1177/0149206311407508

Berglund, K. and Granat Thorslund, J. (2012). Innovative Policies? Entrepreneurship and Innovation Policy from a Gender Perspective, in S. Andersson, K. Berglund, E. Gunnarsson and E. Sundin (eds), Promoting Innovation: Policies, practices, and procedure (pp. 25-46). Stockholm: Vinnova.

Biese, I. (2017). Opting Out and In: On women's careers and new lifestyles. London: Taylor \& Francis. https://doi.org/10.4324/9781315637006

Blackmore, J. and Sawers, N. (2015). Executive Power and Scaled-Up Gender Subtexts in Australian Entrepreneurial Universities. Gender and Education, 27(3), 320-337. https://doi.org/10.1080/ 09540253.2015.1027670

Branch, E. H. (ed). (2016). Pathways, Potholes, and the Persistence of Women in Science: Reconsidering the pipeline. Lanham, MD: Lexington Books.

Braun, V. and Clarke, V. (2006). Using Thematic Analysis in Psychology. Qualitative Research in Psychology, 3(2), $77-$ 101. https://doi.org/10.1191/1478088706qp063oa

Britton, D. M. (2017). Beyond the Chilly Climate: The Salience of Gender in Women's Academic Careers. Gender \& Society, 31(1), 5-27. https://doi.org/10.1177/0891243216681494

Burke, R. J. and Major, D. A. (eds). (2014). Gender in Organizations: Are men allies or adversaries to women's career advancement? Cheltenham: Edward Elgar.

Burr, V. (2015). Social Constructionism. London: Routledge. https:/ / doi.org/10.4324/9781315715421

Callerstig, A. C. (2014). Making Equality Work: Ambiguities, conflicts and change. Agents in the implementation of equality policies in public sector organizations (Doctoral diss.). Linköping: Linköping University. https:// doi.org/10.3384/diss.diva-105207 
Canetto, S. S., Trott, C. D., Winterrowd, E. M., Haruyama, D. and Johnson, A. (2017). Challenges to the Choice Discourse: Women's Views of Their Family and Academic-Science Career Options and Constraints. Journal of Feminist Family Therapy, 29(1-2), 4-27. https:// doi.org/10.1080/08952833.2016.1273174

Caprile, M., Addis, E., Castaño Collado, C. and Klinge, I. (2012). Meta-Analysis of Gender and Science Research: Synthesis report. Brussels: European Commission.

Case, S. S. and Richley, B. A. (2013). Gendered Institutional Research Cultures in Science: The Post-Doc Transition for Women Scientists. Community, Work and Family, 16(3), 327-349. https://doi.org/10.1080/ 13668803.2013.820097

Cederström, C. (2019). State of Nordic Fathers. Copenhagen: Nordic Council of Ministers. https://doi.org/10.6027/e6e6c376-en

Coate, K. and Howson, C. K., 2016. Indicators of Esteem: Gender and Prestige in Academic Work. British Journal of Sociology of Education, 37(4), 567-585. https:// doi.org/10.1080/01425692.2014.955082

Cozzens, S. and Thakur, D. (eds). (2014). Innovation and Inequality: Emerging technologies in an unequal world. Cheltenham: Edward Elgar Publishing.

Diani, M. (2007). The Relational Element in Charles Tilly's Recent (and Not So Recent) Work. Social Networks, 29(2), 316-323. https:// doi.org/10.1016/j.socnet.2006.12.002

Dubois-Shaik, F., Fusulier, B. and Vincke, C. (2019). A Gendered Pipeline Typology in Academia, in A. Murgia and B. Poggio (eds), Gender and Precarious Research Careers (pp. 178-205). London: Routledge. https:// doi.org/10.4324/9781315201245-7

Earhart, A. E., Risam, R. and Bruno, M. (2020). Citational Politics: Quantifying the Influence of Gender on Citation in Digital Scholarship in the Humanities. Digital Scholarship in the Humanities, fqaa011. https://doi.org/10.1093/llc/fqaa011

Edlund, J. and Öun, I. (2016). Who Should Work and Who Should Care? Attitudes Towards the Desirable Division of Labour Between Mothers and Fathers in Five European countries. Acta Sociologica, 59(2), 151-169. https://doi.org/10.1177/0001699316631024

Etzkowitz, H., Kemelgor, C. and Uzzi, B. (2000). Athena Unbound: The advancement of women in science and technology. Cambridge: Cambridge University Press. https://doi.org/10.1017/CBO9780511541414

European Innovation Scoreboard (2019). Available at: https:/ / ec.europa.eu/commission/presscorner/detail/en/ ip_19_2991 (Accessed 20 July 2020).

Evans, C. R. (2019). Reintegrating Contexts into Quantitative Intersectional Analyses of Health Inequalities. Health \& Place, 60, 102214. https://doi.org/10.1016/j.healthplace.2019.102214

Gatrell, C. (2011). Policy and the Pregnant Body at Work: Strategies of Secrecy, Silence and Supra-Performance. Gender, Work and Organization, 18(2), 158-181. https:// doi.org/10.1111/j.1468-0432.2009.00485.x

Gender Equality Barometer (2018). Gender Equality Barometer 2017. Publications of the Ministry of Social Affairs and Health 2/2018, Helsinki: Ministry of Social Affairs and Health. Available at: https://julkaisut.valtioneuvosto.fi/bitstream/handle/10024/161485/STM_12_2018_Gender_Equality_Baro meter_2017_.pdf?sequence=4\&isAllowed=y (Accessed 18 February 2021).

Gender Equality Index (2019). Available at: https://eige.europa.eu/gender-equality-index/compare-countries (Accessed 13 November 2019).

Gill, R. (2010). Breaking the Silence: The Hidden Injuries of the Neoliberal University, in R. Gill and R. RyanFlood (eds), Secrecy and Silence in the Research Process: Feminist reflections (pp. 228-244). Milton Park: Routledge.

Gill, R. and Donaghue, N. (2016). Resilience, Apps, and Reluctant Individualism: Technologies of Self in the Neoliberal Academy. Women's Studies International Forum, 54, 91-99. https://doi.org/10.1016/j.wsif.2015.06.016

Gkiouleka, A., Huijts, T., Beckfield, J. and Bambra, C. (2018). Understanding the Micro and Macro Politics of Health: Inequalities, Intersectionality and Institutions: A Research Agenda. Social Science \& Medicine, 200, 92-98. https://doi.org/10.1016/j.socscimed.2018.01.025

Gordon, T. (2002). Single Women, in G. Griffin and R. Braidotti (eds), Tbinking Differently: A reader in European women's studies (pp. 49-62). London: Zed Books.

Griffin, G. (2019) Intersectionalized Professional Identities and Gender in the Digital Humanities in the Nordic Countries. Work, Employment and Society, 33(6), 966-982. https://doi.org/10.1177/0950017019856821

Götz, N. and Marklund, C. (2014). The Paradox of Openness: Transparency and participation in Nordic cultures of consensus. Leiden: Brill. https://doi.org/10.1163/9789004281196

Henry, C., Smith, H. L., Meschitti, V., Foss, L. and McGowan, P. (2020). Networking, Gender and Academia: An Ecosystems Approach, in H. L. Smith, C. Henry, H. Etzkowitz and A. Poulovassilis (eds), Gender, Science and Innovation: New perspectives (pp.146-167). Cheltenham: Edward Elgar. https://doi.org/10.4337/9781786438973 .00016 
Herschberg, C., Benschop, Y. and Van den Brink, M. (2019). The Peril of Potential: Gender Practices in the Recruitment and Selection of Early Career Researchers, in A. Murgia and B. Poggio (eds). Gender and Precarious Research Careers (pp. 111-142). London: Routledge. https://doi.org/10.4324/9781315201245-5

Holth, L., Bergman, A. and MacKenzie, R. (2017). Gender, Availability and Dual Emancipation in the Swedish ICT Sector. Work, Employment and Society, 31(2), 230-247. https://doi.org/10.1177/0950017016651378

Husu, L. (2001a). Sexism, Support and Survival in Academia: Academic Women and Hidden Discrimination in Finland. Department of Social Psychology, University of Helsinki. Available at: https://www.researchgate.net/publication/274192317_Sexism_support_and_survival_in_academia_the_Fin nish_experience. (Accessed 2 July 2020).

Husu, L. (2001b). Sexism, Support and Survival in Academia: The Finnish Experience, in L. Maxwell, K. Slavin and K. Young (eds), Gender and Research (pp. 203-7). Brussels: European Commission.

Husu, L. (2005). Women's Work- and Family-Related Discrimination and Support in Academia. Advances in Gender Research, 9, 1-40. https://doi.org/10.1016/S1529-2126(05)09007-7

Husu, L. and Cheveigné, S. de (2010). Gender and Gatekeeping of Excellence in Research Funding: European Perspectives, in B. Riegraf, B. Aulenbacher, E. Kirsch-Auwärter and U. Müller (eds), Gender Change in Academia: Remapping the fields of work, knowledge, and politics from a gender perspective (pp. 43-59). Berlin: VS Verlag für Sozialwissenschaften. https://doi.org/10.1007/978-3-531-92501-1_4

Ibarra, H., Ely, R. and Kolb, D. (2013). Women Rising: The Unseen Barriers. Harvard Business Review, 91(9), 60-66.

Jones, K. P., Nittrouer, C. L., Alonso, N. M. and Lindsey, A. P. (2017). Subtle Discrimination in the Workplace: A Vicious Cycle. Industrial and Organizational Psychology, 10(1), 51-76. https://doi.org/10.1017/iop.2016.91

Kanter, R. M. (1977). Men and Women of the Corporation. New York: Basic Books.

Krilic, S. C., Istenic, M. C. and Hocevar, D. K. (2019). Work-life Balance Among Early Career Researchers in Six European Countries, in A. Murgia and B. Poggio (eds). Gender and Precarious Research Careers: A comparative analysis (pp. 145-177). London: Routledge. https://doi.org/10.4324/9781315201245-6

Larivière, V. (2012). On the Shoulders of Students? The Contribution of PhD Students to the Advancement of Knowledge. Scientometrics, 90, 463-491. https://doi.org/10.1007/s11192-011-0495-6

Laslett, B. (2000). The Poverty of (Monocausal) Theory: A Comment on Charles Tilly's Durable Inequality. Comparative Studies in Society and History, 42(2), 475-481. https://doi.org/10.1017/S0010417500002541

Le Feuvre, N., Bataille, P., Kradolfer, S., Del Rio Carral, M. and Sautier, M. (2019). The Gendered Diversification of Academic Career Paths in Comparative Perspective, in A. Murgia and B. Poggio (eds), Gender and Precarious Research Careers (pp. 50-80). London: Routledge. https://doi.org/10.4324/9781315201245-3

Lindberg, M. (2012). A Striking Pattern: Co-Construction of Innovation, Men and Masculinity in Sweden's Innovation Policy, in S. Andersson, K. Berglund, E. Gunnarsson and E. Sundin (eds), Promoting Innovation: Policies, practices, and procedure (pp. 47-67). Stockholm: Vinnova.

Lister, R. (2009). A Nordic Nirvana? Gender, Citizenship, and Social Justice in the Nordic Welfare States. Social Politics, 16(2), 242-278. https://doi.org/10.1093/sp/jxp007

Lund, R., Meriläinen, S. and Tienari, J. (2019). New Masculinities in Universities? Discourses, Ambivalence and Potential Change. Gender, Work and Organization, 26(10), 1376-1397. https://doi.org/10.1111/gwao.12383

Luukkonen-Gronow, T. and Stolte-Heiskanen, V. (1983). Myths and Realities of Role Incompatibility of Woman Scientists. Acta Sociologica, 26(3-4), 267-280. https://doi.org/10.1177/000169938302600304

Lätti, J. (2017). Individualized Sex Equality in Transforming Finnish Academia. European Educational Research Journal, 16(2-3), 258-276. https://doi.org/10.1177/1474904116668184

Mann, M. (1999). Review: The History of all Previous Society is the History of Durable Dichotomies. Contemporary Sociology, 28, 29-30. https:// doi.org/10.2307/2653846

Martinsson. L., Griffin, G. and Giritli-Nygren, K. (eds). (2016). Challenging the Myth of Gender Equality in Sweden. Bristol: Policy Press. https://doi.org/10.1332/policypress/9781447325963.001.0001

Mazur, A. G. (2017) Does Feminist Policy Matter in Post Industrial Democracies? A Proposed Analytical Roadmap. Journal of Women, Politics and Policy, 38(1), 64-83. https:/ / doi.org/10.1080/1554477X.2016.1198210

Merton, R. K. (1988). The Matthew Effect in Science, II: Cumulative Advantage and the Symbolism of Intellectual Property. Isis, 79(4), 606-623. https:// doi.org/10.1086/354848

Morley, L. and Crossouard, B. (2016). Gender in the Neoliberalised Global Academy: The Affective Economy of Women and Leadership in South Asia. British Journal of Sociology of Education, 37(1), 149-168. https://doi.org/10.1080/01425692.2015.1100529

Morris, A. (2000). Building Blocks of Social Inequality: A Critique of Durable Inequality. Comparative Studies in Society and History, 42(2), 482-486. https:/ / doi.org/10.1017/S0010417500002553

Murgia, A. and Poggio, B. (eds). (2019). Gender and Precarious Research Careers: A comparative analysis. London: Routledge. https://doi.org/10.4324/9781315201245 
Nielsen, M. W. (2014). Justification of gender equality in academia: comparing gender equality policies in six Scandinavian universities. Nora, 22(3), 187-203. ttps://doi.org/10.1080/08038740.2014.905490

Nielsen, M. W. (2016). Limits to Meritocracy? Gender in Academic Recruitment and Promotion Processes. Science and Public Policy, 43, 386-399. https://doi.org/10.1093/scipol/scv052

NIKK. (2019). Parental Leave. Available at: https://www.nikk.no/en/facts/in-depth/parental-leave/. (Accessed 11 October 2019).

Nordic Gender Equality in Figures, (2015). Copenhagen: The Nordic Council of Ministers. https://doi.org/10.6027/ANP2015-768

OECD. (2017). OECD Reviews on Innovation Policy: Finland. Available at: https:/ / read.oecd-ilibrary.org/science-andtechnology/oecd-reviews-of-innovation-policy-finland-2017_9789264276369-en\#page20. (Accessed 04 June 2019).

Orgad, S. (2019). Heading Home: Motherhood, work and the failed promise of equality. New York: Columbia University Press. https://doi.org/10.7312/orga18472

Pecis, L. (2016). Doing and Undoing Gender in Innovation: Femininities and Masculinities in Innovation Processes. Human Relations, 69(11), 2117-2140. https:// doi.org/10.1177/0018726716634445

Pecis, L. and Priola, V. (2019). The 'New Industrial Man' as Unhero: Doing Postfeminist Masculinities in an Italian Pharmacological Research Centre. Gender, Work and Organization, 26(10), 1413-1432. https://doi.org/10.1111/gwao.12359

Research Careers in Sweden. Available at: https://www.eui.eu/ProgrammesAndFellowships/ AcademicCareersObservatory/AcademicCareersbyCountry/Sweden. (Accessed 1 May 2020).

Rolin, K. and Vainio, J. (2011). Gender in Academia in Finland: Tensions between Policies and Gendering Processes in Physics Departments. Science and Technology Studies, 24(1), 26-46. https://doi.org/10.23987/sts.55268

Rose, S. (1989). Women Biologists and the 'Old Boy’ Network. Women's Studies International Forum, 12(3), 349-354. https://doi.org/10.1016/S0277-5395(89)80011-1

Salminen-Karlsson, M., Wolffram, A. and Almgren, N. (2018). Excellence, Masculinity and Work-Life Balance in Academia: Voices from Researchers in Germany and Sweden. International Journal of Gender, Science and Technology, 10(1), 52-71.

Scholz, B., Vuorio, E., Matuschek, S. and Cameron, I. (2009). Research Careers in Europe: Landscapes and Horizons. Strasbourg: European Science Foundation. Available at: https://www.norden.org/en/publication/statenordic-fathers. (Accessed 8 May 2020).

Seron, C., Silbey, S., Cech, E. and Rubineau, B. (2018). 'I am not a Feminist, but...': Hegemony of a Meritocratic Ideology and the Limits of Critique Among Women in Engineering. Work and Occupations, 45(2), 131-167. https://doi.org/10.1177/0730888418759774

SHE Figures (2018) Brussels: European Commission. Available at: https://ec.europa.eu/info/publications/shefigures-2018_en. (Accessed 3 October 2019).

Siekkinen, T., Kuoppala, K., Pekkola, E. and Välimaa, J. (2017). Reciprocal Commitment in Academic Careers? Finnish Implications and International Trends. European Journal of Higher Education, 7(2), 120-135. https://doi.org/10.1080/21568235.2016.1248990

Silius, H. (2002). Feminist Perspectives on the European Welfare States, in G. Griffin and R. Braidotti (eds), Thinking Differently: A reader in European women's studies (pp. 31-48). London: Zed Books.

Slaughter, S. and Leslie, L. L. (1997). Academic Capitalism: Politics, policies, and the entrepreneurial university. Baltimore: Johns Hopkins University Press.

Slaughter, S., Slaughter, S. A. and Rhoades, G. (2004). Academic Capitalism and the New Economy: Markets, state, and higher education. Baltimore: Johns Hopkins University Press.

Svalund, J. and Berglund, T. (2018). Fixed-Term Employment in Norway and Sweden: A Pathway to Labour Market Marginalization? European Journal of Industrial Relations, 24(3), 261-277. https://doi.org/10.1177/0959680117740777

Sørensen, S. Ø. (2017). The Performativity of Choice: Postfeminist Perspectives on Work-Life Balance. Gender, Work \& Organization, 24(3), 297-313. https://doi.org/10.1111/gwao.12163

Thun, C. (2020). Excellent and Gender Equal? Academic Motherhood and 'Gender Blindness' in Norwegian Academia. Gender, Work and Organization, 27(2), 166-180. https://doi.org/10.1111/gwao.12368

Tiainen, T. and Berki, E. (2019). The Re-Production Process of Gender Bias: A Case of ICT Professors Through Recruitment in a Gender-Neutral Country. Studies in Higher Education, 44(1), 170-184. https://doi.org/10.1080/03075079.2017.1351428

Tilly, C. (1998). Durable Inequality. Berkeley: University of California Press. https://doi.org/10.1525/ 9780520924222 
Tilly, C. (2001). Relational Origins of Inequality. Anthropological Theory, 1(3), 355-372. https://doi.org/10.1177/ 14634990122228773

Tomaskovic-Devey, D. (2014). The Relational Generation of Workplace Inequalities. Social Currents, 1(1), 51-73. https://doi.org/10.1177/2329496513514032

Tomaskovic-Devey, D., Avent-Holt, D., Zimmer, C. and Harding, S. (2009). The Categorical Generation of Organizational Inequality: A Comparative Test of Tilly's Durable Inequality. Research in Social Stratification and Mobility, 27(3), 128-142. https://doi.org/10.1016/j.rssm.2009.04.004

Van den Brink, M. and Benschop, Y. (2011). Gender Practices in the Construction of Academic Excellence: Sheep with Five Legs. Organization, 19(4), 507-524. https://doi.org/10.1177/1350508411414293

Van den Brink, M. and Benschop, Y. (2012). Slaying the Seven-Headed Dragon: The Quest for Gender Change in Academia. Gender, Work and Organization, 19(1), 71-92. https://doi.org/10.1111/j.1468-0432.2011.00566.x

Van den Brink, M. and Benschop, Y. (2014). Gender in academic networking: The role of gatekeepers in professorial recruitment. Joumal of Management Studies, 51(3), 460-492. https://doi.org/10.1111/joms.12060

Vehviläinen, M., Vuolanto, P. and Ylijoki, O. H. (2010). Gender Equality in Interface Organizations Between Science, Technology and Innovation. Journal of Technology Management and Innovation, 5(1), 64-74. https://doi.org/10.4067/S0718-27242010000100005

Wall, S. (2008). Of Heads and Hearts: Women in Doctoral Education at a Canadian University. Women's Studies International Forum, 31(3 May-June), 219-228. https:/ / doi.org/10.1016/j.wsif.2008.04.007

Williams, J. C., Phillips, K. W. and Hall, E. W. (2016). Tools for Change: Boosting the Retention of Women in the STEM Pipeline. Journal of Research in Gender Studies, 6(1), 11-75. https://doi.org/10.22381/JRGS6120161

Winslow, S. and Davis, S. N. (2016). Gender Inequality across the Academic Life Course. Sociology Compass, 10(5), 404-416. https://doi.org/10.1111/soc4.12372

Ylöstalo, H. (2016). Traces of Equality Policy and Diversity Management in Finnish Work Organizations. Equality, Diversity and Inclusion: An International Journal, 35(7-8), 415-428. https:// doi.org/10.1108/EDI-12-2015-0104

Citation: Griffin, G. and Vehviläinen, M. (2021). The Persistence of Gender Struggles in Nordic Research and Innovation. Feminist Encounters: A Journal of Critical Studies in Culture and Politics, 5(2), 28. https://doi.org/10.20897/femenc/11165

Copyright (C) 2021 by Author/s and Licensed by Lectito BV, Netherlands. This is an open access article distributed under the Creative Commons Attribution License which permits unrestricted use, distribution, and reproduction in any medium, provided the original work is properly cited. 